Research Paper

\title{
The Clinical and Biomarker Association of Programmed Death Ligand 1 and its Spatial Heterogeneous Expression in Colorectal Cancer
}

\author{
Xiao-Li Wei1*, Qi-Nian Wu ${ }^{2 *}$, Dong-liang Chen ${ }^{1 *}$, Zhao-Lei Zeng ${ }^{2}$, Jia-Bin Lu' ${ }^{3}$, Ze-Xian Liu ${ }^{2}$, Huai-Qiang \\ $\mathrm{Ju}^{2}$, Chao Ren ${ }^{1}$, Zhi-Zhong Pan ${ }^{4}$, Feng-Hua Wang ${ }^{\bowtie}$, Rui-Hua $\mathrm{Xu}^{1}{ }^{\bowtie}$ \\ 1. Department of Medical Oncology, Sun Yat-sen University Cancer Center, State Key Laboratory of Oncology in South China, Collaborative Innovation \\ Center for Cancer Medicine, Guangzhou 510060, China. \\ 2. State Key Laboratory of Oncology in South China, Sun Yat-sen University Cancer Center, Collaborative Innovation Center for Cancer Medicine, Guangzhou \\ 510060, China. \\ 3. Department of Pathology, Sun Yat-sen University Cancer Center, State Key Laboratory of Oncology in South China, Collaborative Innovation Center for \\ Cancer Medicine, Guangzhou 510060, China. \\ 4. Department of Colorectal Surgery, Sun Yat-sen University Cancer Center, State Key Laboratory of Oncology in South China, Collaborative Innovation \\ Center for Cancer Medicine, Guangzhou 510060, China. \\ *Xiao-Li Wei, Qi-Nian Wu and Dong-liang Chen contributed equally to this study.
}

$\triangle$ Corresponding authors: Feng-Hua Wang, Department of Medical Oncology, Sun Yat-sen University Cancer Center, State Key Laboratory of Oncology in South China, Collaborative Innovation Center for Cancer Medicine, 651 Dong Feng Road East, Guangzhou 510060, Guangdong Province, China. wangfh@sysucc.org.cn. Telephone: +86-20-8734 2297, Fax: +86-20-8734 2297 or Rui-Hua Xu, Department of Medical Oncology, Sun Yat-sen University Cancer Center, State Key Laboratory of Oncology in South China, Collaborative Innovation Center for Cancer Medicine, 651 Dong Feng Road East, Guangzhou 510060, Guangdong Province, China. xurh@sysucc.org.cn. Telephone: +86-20-8734 3468, Fax: +86-20-8734 3468

(c) Ivyspring International Publisher. This is an open access article distributed under the terms of the Creative Commons Attribution (CC BY-NC) license (https://creativecommons.org/licenses/by-nc/4.0/). See http://ivyspring.com/terms for full terms and conditions.

Received: 2018.06.07; Accepted: 2018.08.10; Published: 2018.10.21

\begin{abstract}
Background: Programmed death ligand 1 (PD-LI) expression has been shown to predict benefit from anti-PD-1 treatment in several cancers. However, its predictive value in colorectal cancer seems limited. This study was aimed to explore the clinical and biomarker association of programmed death ligand 1 and its spatial heterogeneous expression in colorectal cancer.

Methods: Tissue microarrays of 422 primary colorectal cancers from our hospital were used for the interpretation of PD-L1 and programmed death 1 (PD-1) expression, cluster of differentiation 4 (CD4) and CD8 density and microsatellite instability (MSI) status by immunohistochemistry. To assess the spatial heterogeneity of PD-LI expression, Tissue microarrays of 383 paired intra-primary-tumor tissues, and 105 paired lymph node metastatic tumors and 64 paired distant metastatic tumors were also used.

Results: PD-L1 was positive in 188 (44.5\%) primary colorectal cancers. PD-L1 expression was associated with less advanced $N$ category $(P<0.001)$, less advanced TNM stage $(P<0.001)$ and less nervous invasion $(P=0.04)$. Higher PD-L1 expression was associated with higher PD-1 expression $(P<0.001)$, higher CD4 $(P<0.001)$ and CD8 $(P<0.001)$ density and DNA mismatch repair deficiency $(P=0.01)$. PD-L1 expression was associated with better disease-free survival and overall survival, but it was only an independent prognostic factor for disease-free survival (hazard ratio and 95\% confidence interval: 0.42 [0.25-0.72], $P<0.001$ ). The probability of inconsistent PD-LI expression was respectively $17.8 \%, 31.4 \%$ and $39.1 \%$ within primary tumors, between primary tumors and lymph node metastatic tumors, and between primary tumors and distant metastatic tumors. All the three differences were statistically significant $(P<0.001, P<0.001$ and $P=0.05$, respectively).

Conclusions: PD-LI expression was a marker of pre-existing immune responses in colorectal cancer, however, it was heterogeneously expressed in colorectal cancer, especially between primary and metastatic tumors. This might partially explain the low-efficiency of its predictive value for benefit from anti-PD-1 treatment.
\end{abstract}

Key words: colorectal cancer; programmed death ligand 1; microsatellite instability; tumor-infiltrating immune cells; heterogeneity 


\section{Introduction}

Immune checkpoint blockade has emerged as the most promising modality of immunotherapy in cancer ${ }^{1,2}$. The programmed death 1 (PD-1)/ programmed death ligand 1 (PD-L1) pathway is the most profoundly developed target of immune checkpoint blockade therapy. Pembrolizumab and nivolumab, two PD-1 inhibitors, have been approved by the Food and Drug Administration (FDA) for the treatment of several cancers, including melanoma, non-small cell lung cancer, head and neck squamous cell carcinoma, renal cell carcinoma and classical Hodgkin's lymphoma, basing on their inspiring performance in clinical trials ${ }^{3-11}$. Their anti-tumor effects are also widely investigated in other cancers, with colorectal cancer (CRC) included. The immune-related objective response rate was $40 \%$ in CRC with mismatch-repair deficiency (dMMR) treated with pembrolizumab in a phase II clinical trial $^{10}$.

The PD-1/PD-L1 axis is an immune checkpoint which limits T-cell activity and repress immune responses ${ }^{1}$. As a negative feedback system, it is upregulated at the activation of Th1 cytotoxic immune responses. PD-L1 has been proved to be related with clinicopathological characteristics and prognosis in a variety of cancers ${ }^{12-15}$. In addition, there have been considerable evidences that PD-L1 is correlated with increased tumor-infiltrating lymphocytes (TIL) and is an indicator of pre-existing adaptive immune responses in various cancers $12,13,16$. The expression of PD-L1 is a possible predictive factor for benefit from anti-PD-1 treatment in several cancers, although its value is still debatable in certain aspects ${ }^{4}, 6,17$. In several cancers, the FDA has approved usage of PD-1 antibody in PD-L1 positive tumors.

However, in a study recruiting PD-L1 positive colorectal cancer to receive anti-PD-1 therapy (KEYNOTE-028), PD-L1 positivity didn't efficiently gather target population. In addition, the correlations of PD-L1 expression with microsatellite instability (MSI) and TIL are still controversial based on previous studies ${ }^{18-22}$. Tumor heterogeneity has been widely reported ${ }^{23-26}$. For example, the rate of discordance of KRAS mutation status between primary and metastatic tumors was about $20 \%$ in Chinese CRC patients according to our previous study ${ }^{27}$. In order to help explain the mechanism of inefficient predictive value of PD-L1 expression for benefit from anti-PD-1 treatment in CRC, we conducted this study to explore the clinicopathological and biomarker relevance and heterogeneity of PD-L1 expression within primary tumors and between primary and metastatic tumors in a relatively large CRC patient sample.

\section{Materials and Methods}

\section{Ethics statement}

All patients have signed written informed consent for their information and biological samples to be stored and analyzed in the hospital database of Sun Yat-sen University Cancer Center. Study approval was obtained from our independent ethics committee. The approval number is YB2016-075. This study was conducted in accordance with the ethical standards of the World Medical Association Declaration of Helsinki.

\section{Study group}

A total of 459 pathologically confirmed primary CRCs with formalin-fixed, paraffin-embedded tissue blocks archived in Sun Yat-sen University Cancer Center during January, 2002 to December, 2012 were screened for this study. Information about clinicopathological characteristics and survival status were carefully collected directly from electronic information system. Age, sex, year of diagnosis, primary site, $\mathrm{M}$ category, and information for tumor recurrence or metastasis, as well as overall survival were collected from Electronic Medical Record (EMR) system. T category, $\mathrm{N}$ category, and tumor differentiation were collected from Laboratory Information System (LIS). Nervous invasion, venous invasion and tumor deposits were evaluated by an experienced pathologist. Finally, after excluding 87 cases with incomplete information, all the remaining 422 cases were included in this study. All patients had the resection of primary tumors. None of them received preoperative chemotherapy or radiotherapy, considering that PD-L1 expression status might be affected by anti-tumor treatment.

\section{Tissue microarray (TMA) construction}

H\&E-stained slides were reviewed by an experienced pathologist and areas with abundant tumor cells were marked to guide core selection. Tissue cylinders with $0.6 \mathrm{~mm}$ diameter were removed from donor tissue blocks to TMA tissue blocks. Each TMA block had a total of about 400 cores. TMAs of primary CRC tumors from the 422 cases were constructed for the analysis of PD-L1 and PD-1 expression, cluster of differentiation 4 (CD4) and CD8 density, as well as MSI status by immunohistochemistry (IHC). To explore the concordance of PD-L1 expression in CRC, TMAs of another location in primary tumors, lymph node metastasis and distant metastasis were also constructed. Intra-tumoral heterogeneity of PD-L1 expression in primary CRCs could be assessed in 383 paired tumors. Concordances of PD-L1 expression between primary tumors and 
paired lymph node and distant metastatic tumors were assessable respectively in 105 and 64 cases.

\section{Immunohistochemistry}

Paraffin-embedded TMA samples were cut into $4 \mu \mathrm{m}$ sections. Rabbit antibodies for PD-L1 (SP142, spring bioscience), PD-1 (SP269, spring bioscience), CD4 (ZA-0519, ZSGB-BIO), CD8 (ZA-0508, ZSGBBIO), MLH1 (ZM-0154, ZSGB-BIO), MSH2 (ZA-0622, ZSGB-BIO), MSH6 (ZA-0541, ZSGB-BIO) and PMS2 (ZA-0542, ZSGB-BIO) were used. All the primary antibodies we used were also clinically applied in pathology department of our hospital. IHC assays were performed as follows. Briefly, the tissue sections were baked, deparaffinized and rehydrated. Endogenous peroxide was blocked by incubating with 3\% hydrogen peroxide in methanol for 15 minutes at $37^{\circ} \mathrm{C}$. Then processed for antigen retrieval by high pressure cooking in EDTA antigen retrieval solution $(\mathrm{pH}=8)$ for about 10 minutes. Sections were incubated with primary antibodies at $37^{\circ} \mathrm{C}$ for about 1.5h. After washing, tissue sections were treated with HRP RABBIT/MOUSE secondary antibody (K5007, 20029103, Dako) for 30 minutes at room temperature. The sections were immunostained with diaminobenzidine tetrahydrochloride (DAB, K5007, 20019193, Dako) and counterstained with hematoxylin. Immune cells in the lymphoid tissue within normal colorectal tissue cores served as positive controls for the staining of PD-L1, PD-1, CD4 and CD8.

\section{Evaluation of PD-L1 and PD-1 expression, CD4 and CD8 density, as well as MSI status}

All slides were interpreted by a pathologist blinded to patient information. PD-L1 expression was studied based on immunostaining on the membrane of both tumor cells and tumor-infiltrating immune cells, while PD-1 expression, CD4 and CD8 density based on immunostaining on the membrane of tumor-infiltrating immune cells. The proportion of cells with positive staining in relation to the cells of whole carcinoma area was recorded. The definitions of PD-L1 expression (negative/positive, absent and low/moderate/high), PD-1 expression (negative/ positive, absent and low/moderate/high), CD4 density (absent and low/moderate/high), and CD8 density (absent and low/moderate/high) in this study were shown in Supplementary Table 1.

Nuclear immunostaining was evaluated for the expression of MLH1, MSH2, MSH6 and PMS2. Expression of all the four indexes was considered as DNA mismatch repair proficiency (pMMR). Otherwise, absent expression in any of the above four indexes was considered as dMMR.

\section{Statistical analysis}

The statistical analyses were performed with SPSS for Windows V.13.0 (SPSS Inc., Chicago, IL, USA). A two tailed $P$ value $<0.05$ was considered statistically significant. The association of PD-L1 expression with clinicopathological characteristics, PD-1 expression, CD4 density, CD8 density and MSI status was assessed using chi-square test or Kruskal-Wallis $\mathrm{H}$ test based on the type of comparisons. The concordance of PD-L1 expression in CRC was evaluated with chi-square test. Disease-free survival (DFS) was calculated as the time interval between CRC diagnosis and CRC recurrence or metastasis. Overall survival (OS) was calculated as the time interval between CRC diagnosis and the death attributed to CRC or censored at death from other causes or the last visit. Univariate and multivariate logistical regression analyses were performed for the prognostic value of PD-L1 expression for DFS and OS. Survival curves were plotted by the Kaplan-Meier method and compared using the log-rank test. Hazard ratio and 95\% confidence interval (HR and 95\% CI) was computed with the cox proportional hazards model.

\section{Results}

\section{Clinicopathological characteristics of patients with CRC in this study}

A total of 422 cases with CRC were included in this study. Among them, there were 249 (59.0\%) males and $173(41.0 \%)$ females. The median age was 56 years old, ranging from 24 to 83 years old. Two hundred and forty nine $(59.0 \%)$ cases were diagnosed from 2002 to 2008, and the rest $173(41.0 \%)$ cases were diagnosed from 2009 to 2012. The numbers of cases with primary tumor located at right colon, left colon and rectum were respectively 110 (26.1\%), 119 (28.2\%) and $193(45.7 \%)$. There were respectively $27(6.4 \%)$, $122(28.9 \%), 205(48.6 \%)$ and 68 (16.1\%) cases diagnosed at stage I, II, III and IV. The median follow-up time was 72 months. During the follow up, there were 99 (30.0\% of stage I to III population) cases experiencing CRC recurrence or metastasis and 103 ( $24.4 \%$ of the total) cases died from CRC.

\section{The correlation of PD-LI expression with basic clinicopathological characteristics}

Table 1 showed the details for the correlation of PD-L1 expression with basic features. All the cases were classified into two subgroups according to PD-L1 expression, positive expression $(n=188,44.5 \%)$ with $\geq 1 \%$ immunostaining in tumor-infiltrating immune cells and/or $\geq 5 \%$ immunostaining in tumor cells, otherwise negative expression $(n=234,55.5 \%)$. 
PD-L1 expression was found to be associated with less advanced $\mathrm{N}$ category $(P<0.001)$ and less nervous invasion $(P=0.04)$. From stage $\mathrm{I}$ to stage $\mathrm{IV}$, the positive rates of PD-L1 expression were generally decreasing, from $63 \%, 58.2 \%, 36.1 \%$ to $38.2 \%$ $(P<0.001)$. In addition, there was a trend of correlation between higher PD-L1 expression and less advanced $\mathrm{T}$ category $(P=0.07)$. There were no significant association of PD-L1 expression with age $(\leq 56 />56$ years), sex (male/female), year of diagnosis ( 2008/ 2009 ), primary site (right colon/left colon/rectum), $\mathrm{M}$ category (M0/M1), tumor differentiation (poorly differentiated or undifferentiated/moderately or well differentiated), venous invasion (negative/positive) and tumor deposits (negative/ positive).

Table 1. The clinicopathological relevance of PD-LI expression in colorectal cancer.

\begin{tabular}{|c|c|c|c|}
\hline \multirow[t]{2}{*}{ Characteristics } & \multicolumn{2}{|l|}{ PD-L1 expression } & \multirow[t]{2}{*}{$P$ value } \\
\hline & Negative, No. (\%) & Positive, No. (\%) & \\
\hline Age (years, median 56) & & & 0.45 \\
\hline$\leq 56$ & $122(57.3)$ & $91(42.7)$ & \\
\hline$>56$ & $112(53.6)$ & $97(46.4)$ & \\
\hline Sex & & & 0.54 \\
\hline Male & $135(54.2)$ & $114(45.8)$ & \\
\hline Female & $99(57.2)$ & $74(42.8)$ & \\
\hline Year of diagnosis & & & 0.42 \\
\hline$\sim 2008$ & $134(53.8)$ & $115(46.2)$ & \\
\hline $2009 \sim$ & $100(47.8)$ & $73(42.2)$ & \\
\hline Primary site & & & 0.91 \\
\hline Right colon & $62(56.4)$ & $48(43.6)$ & \\
\hline Left colon & $64(53.8)$ & $55(46.2)$ & \\
\hline Rectum & $108(56.0)$ & $85(44.0)$ & \\
\hline T category & & & 0.07 \\
\hline $\mathrm{T} 1+2$ & $18(45.0)$ & $22(55.0)$ & \\
\hline T3 & $162(54.9)$ & $133(45.1)$ & \\
\hline $\mathrm{T} 4$ & $54(62.1)$ & $33(37.9)$ & \\
\hline $\mathrm{N}$ category & & & $<0.001$ \\
\hline No & $70(41.4)$ & $99(58.6)$ & \\
\hline N1 & $93(67.4)$ & $45(32.6)$ & \\
\hline N2 & $71(61.7)$ & $44(38.3)$ & \\
\hline M category & & & 0.25 \\
\hline M0 & $192(54.2)$ & $162(45.8)$ & \\
\hline M1 & $42(61.8)$ & $26(38.2)$ & \\
\hline TNM stage & & & $<0.001$ \\
\hline I & $10(37.0)$ & $17(63.0)$ & \\
\hline II & $51(41.8)$ & $71(58.2)$ & \\
\hline III & 131 (63.9) & $74(36.1)$ & \\
\hline IV & $42(61.8)$ & $26(38.2)$ & \\
\hline Tumor differentiation & & & 0.57 \\
\hline $\begin{array}{l}\text { Poorly differentiated or } \\
\text { undifferentiated }\end{array}$ & $28(51.9)$ & $26(48.1)$ & \\
\hline $\begin{array}{l}\text { Moderately or well } \\
\text { differentiated }\end{array}$ & $206(56.0)$ & $162(44.0)$ & \\
\hline Nervous invasion & & & 0.04 \\
\hline Negative & 147 (51.9) & $136(48.1)$ & \\
\hline Positive & $87(62.6)$ & $52(37.4)$ & \\
\hline Venous invasion & & & 0.40 \\
\hline Negative & $207(54.8)$ & $171(45.2)$ & \\
\hline Positive & $27(61.4)$ & $17(38.6)$ & \\
\hline Tumor deposits & & & 0.20 \\
\hline Negative & $202(54.3)$ & $170(45.7)$ & \\
\hline Positive & $32(64.0)$ & $18(36.0)$ & \\
\hline
\end{tabular}

Abbreviations: PD-L1, programmed death ligand 1.
The correlation of PD-LI expression with MSI status, PD-1 expression, and CD4 and CD8 density

According to PD-L1 immunostaining in tumorinfiltrating immune cells and tumor cells, all the cases were categorized into three subgroups: absent and low expression group, moderate expression group and high expression group. The method for the categorization was shown in Supplementary Table 1. Similar classifications of PD-1 expression, CD4 density and CD8 density were also performed according to the method listed in Supplementary Table 1. Cases with dMMR had higher expression of PD-L1 $(P=0.01)$. Higher PD-L1 expression was also found to be significantly associated with higher PD-1 expression $(P<0.001)$, higher $\mathrm{CD} 4$ density $(P<0.001)$ and higher CD8 density $(P<0.001)$. Details were listed in Table 2. Representative immunostaining of PD-L1, PD-1, CD4 and CD8 was shown in Figure 1.

Table 2. The correlation of PD-LI expression with MSI status, PD-1 expression, CD4 and CD8 density in colorectal cancer.

\begin{tabular}{|c|c|c|c|c|}
\hline \multirow[t]{2}{*}{ Characteristics } & \multicolumn{3}{|c|}{ PD-L1 expression, $n(\%)$} & \multirow[t]{2}{*}{$P$ value } \\
\hline & Absent and Low & Moderate & High & \\
\hline MSI & & & & 0.01 \\
\hline dMMR & $64(59.8)$ & $15(14.0)$ & $28(26.2)$ & \\
\hline pMMR & $238(75.6)$ & $31(9.8)$ & $46(14.6)$ & \\
\hline PD-1 expression & & & & $<0.001$ \\
\hline Absent and Low & $290(74.0)$ & $43(11.0)$ & $59(15.1)$ & \\
\hline Moderate & $5(50.0)$ & $1(10.0)$ & $4(40.0)$ & \\
\hline High & $7(35.0)$ & $2(10.0)$ & $11(55.0)$ & \\
\hline CD4 density & & & & $<0.001$ \\
\hline Absent and Low & $247(77.9)$ & $29(9.1)$ & $41(12.9)$ & \\
\hline Moderate & $47(56.0)$ & $16(19.0)$ & $21(25.0)$ & \\
\hline High & $8(38.1)$ & $1(4.8)$ & $12(57.1)$ & \\
\hline CD8 density & & & & $<0.001$ \\
\hline Absent and Low & $265(80.8)$ & $28(8.5)$ & $35(10.7)$ & \\
\hline Moderate & $34(47.9)$ & $15(21.1)$ & $22(31.0)$ & \\
\hline High & $3(13.0)$ & $3(13.0)$ & $17(73.9)$ & \\
\hline
\end{tabular}

\section{The prognostic value of PD-LI expression for DFS and OS in CRC}

We further evaluated the prognostic value of PD-L1 expression (negative/ positive) for DFS in cases at stage I to III $(n=354)$ and for OS in the total population $(n=422)$. Details were shown in Table 3 . There were only 68 cases at stage IV and the influence of PD-L1 expression on progression-free survival (PFS) was not assessed due to small sample size.

For DFS, only $\mathrm{N}$ category (N0/N1/N2) and PD-L1 expression (negative/ positive) were significant prognostic factors by univariate analysis. After adjusting by $\mathrm{N}$ category, PD-L1 expression remained to be 
independently prognostic for DFS (HR and 95\% CI: superior DFS in CRC. The survival curves plotted by $0.42(0.25-0.72), P<0.001)$. PD-L1 expression predicted

Table 3. Univariate and multivariate Cox proportional hazards analysis for DFS and OS in colorectal cancer.

\begin{tabular}{|c|c|c|c|c|c|c|c|c|c|c|}
\hline \multirow[t]{3}{*}{ Characteristics } & \multicolumn{5}{|c|}{ DFS } & \multicolumn{5}{|c|}{ OS } \\
\hline & \multicolumn{3}{|c|}{ Univariate analysis } & \multicolumn{2}{|c|}{ Multivariate analysis } & \multicolumn{2}{|c|}{ Univariate analysis } & & \multicolumn{2}{|c|}{ Multivariate analysis } \\
\hline & Number & $H R(95 \% C I)$ & $P$ value & HR $(95 \% C I)$ & $P$ value & Number & HR $(95 \% C I)$ & $P$ value & HR $(95 \% C I)$ & $P$ value \\
\hline Age & & $1.26(0.79-2.01)$ & 0.34 & & & & $1.23(0.83-1.81)$ & 0.30 & & \\
\hline$\leq 56$ & $174(49.2)$ & & & & & $213(50.5)$ & & & & \\
\hline$>56$ & $180(50.8)$ & & & & & $209(49.5)$ & & & & \\
\hline Sex & & $0.64(0.39-1.05)$ & 0.08 & & & & $0.55(0.36-0.84)$ & 0.01 & $0.57(0.37-0.88)$ & 0.01 \\
\hline Male & $205(57.9)$ & & & & & $249(59.0)$ & & & & \\
\hline Female & $149(42.1)$ & & & & & $173(41.0)$ & & & & \\
\hline Year of diagnosis & & $1.42(0.89-2.27)$ & 0.15 & & & & $0.68(0.45-1.05)$ & 0.08 & & \\
\hline$\sim 2008$ & $217(61.3)$ & & & & & $249(59.0)$ & & & & \\
\hline $2009 \sim$ & $137(38.7)$ & & & & & $173(41.0)$ & & & & \\
\hline Primary site & & & 0.23 & & & & & 0.31 & & \\
\hline Right colon & $89(25.1)$ & 1 & Reference & & & $110(26.1)$ & 1 & Reference & & \\
\hline Left colon & $100(28.2)$ & $0.97(0.49-1.95)$ & 0.94 & & & $119(28.2)$ & $0.70(0.41-1.22)$ & 0.21 & & \\
\hline Rectum & $165(46.6)$ & $1.48(0.82-2 / 69)$ & 0.19 & & & $193(45.7)$ & $1.02(0.64-1.62)$ & 0.94 & & \\
\hline T category & & & 0.29 & & & & & $<0.001$ & & 0.02 \\
\hline $\mathrm{T} 1+2$ & $38(10.7)$ & 1 & Reference & & & $40(9.5)$ & 1 & Reference & 1 & Reference \\
\hline $\mathrm{T} 3$ & $251(70.9)$ & $1.30(0.56-3.04)$ & 0.55 & & & $295(69.9)$ & $1.20(0.55-2.64)$ & 0.65 & $0.67(0.30-1.51)$ & 0.34 \\
\hline $\mathrm{T} 4$ & $65(18.4)$ & $1.90(0.75-4.84)$ & 0.18 & & & 87 (20.6) & $2.87(1.28-6.44)$ & 0.01 & $1.21(0.52-2.81)$ & 0.66 \\
\hline $\mathrm{N}$ category & & & $<0.001$ & & & & & $<0.001$ & & 0.001 \\
\hline No & $152(42.9)$ & 1 & Reference & 1 & Reference & $169(40.0)$ & 1 & Reference & 1 & Reference \\
\hline N1 & $121(34.2)$ & $1.04(0.56-1.93)$ & 0.90 & $\begin{array}{l}0.86 \\
(0.46-1.60)\end{array}$ & 0.63 & $138(32.7)$ & $2.09(1.19-3.68)$ & 0.01 & $2.27(1.25-4.13)$ & 0.01 \\
\hline N2 & $81(22.9)$ & $3.43(2.00-5.90)$ & $<0.001$ & $\begin{array}{l}2.97 \\
(1.72-5.13)\end{array}$ & $<0.001$ & $115(27.3)$ & $4.81(2.87-8.08)$ & $<0.001$ & $2.98(1.68-5.31)$ & $<0.001$ \\
\hline M category & & & & & & & $5.51(3.66-8.31)$ & $<0.001$ & $4.18(2.65-6.60)$ & $<0.001$ \\
\hline M0 & - & - & & & & $354(83.9)$ & & & & \\
\hline M1 & - & - & & & & $68(16.1)$ & & & & \\
\hline $\begin{array}{l}\text { Tumor } \\
\text { differentiation }\end{array}$ & & $1.48(0.79-2.74)$ & 0.22 & & & & $0.48(0.30-0.78)$ & 0.003 & $0.55(0.33-0.92)$ & 0.02 \\
\hline $\begin{array}{l}\text { Poorly differentiated } \\
\text { or undifferentiated }\end{array}$ & 49 (13.8) & & & & & $54(12.8)$ & & & & \\
\hline $\begin{array}{l}\text { Moderately or well } \\
\text { differentiated }\end{array}$ & $305(86.2)$ & & & & & $368(87.2)$ & & & & \\
\hline Nervous invasion & & $1.38(0.87-2.21)$ & 0.17 & & & & $0.87(0.57-1.33)$ & 0.53 & & \\
\hline Negative & $217(61.3)$ & & & & & $283(67.1)$ & & & & \\
\hline Positive & $137(38.7)$ & & & & & $139(32.9)$ & & & & \\
\hline Venous invasion & & $1.12(0.54-2.35)$ & & & & & $1.64(0.95-2.85)$ & 0.08 & & \\
\hline Negative & $315(89.0)$ & & & & & $378(89.6)$ & & & & \\
\hline Positive & $39(11.0)$ & & & & & $44(10.4)$ & & & & \\
\hline Tumor deposits & & $1.78(0.91-3.48)$ & 0.09 & & & & $2.51(1.56-4.02)$ & $<0.001$ & $1.16(0.69-1.97)$ & 0.57 \\
\hline Negative & $319(90.1)$ & & & & & $372(88.2)$ & & & & \\
\hline Positive & $35(9.9)$ & & & & & $50(11.8)$ & & & & \\
\hline PD-L1 expression & & $0.40(0.24-0.68)$ & 0.001 & $\begin{array}{l}0.42 \\
(0.25-0.72)\end{array}$ & 0.001 & & $0.61(0.41-0.92)$ & 0.02 & $0.81(0.53-1.23)$ & 0.31 \\
\hline Negative & $192(54.2)$ & & & & & $234(55.5)$ & & & & \\
\hline Positive & $162(45.8)$ & & & & & $188(44.5)$ & & & & \\
\hline PD-1 expression & & $0.62(0.29-1.36)$ & 0.23 & & & & 1.05 (0.63-1.78) & 0.84 & & \\
\hline Negative & $304(85.8)$ & & & & & $353(83.6)$ & & & & \\
\hline Positive & $50(14.1)$ & & & & & $69(16.4)$ & & & & \\
\hline CD4 density & & & 0.16 & & & & & 0.14 & & \\
\hline Absent and Low & $266(75.1)$ & 1 & Reference & & & $317(75.1)$ & 1 & Reference & & \\
\hline Moderate & 69 (19.5) & $0.68(0.35-1.29)$ & 0.23 & & & $84(19.9)$ & $0.69(0.40-1.18)$ & 0.18 & & \\
\hline High & $19(5.4)$ & $0.21(0.03-1.49)$ & 0.12 & & & $21(5.0)$ & $0.33(0.08-1.34)$ & 0.12 & & \\
\hline CD8 density & & & 0.13 & & & & & 0.10 & & \\
\hline Absent and Low & $266(75.1)$ & 1 & Reference & & & $328(77.7)$ & 1 & Reference & & \\
\hline Moderate & $65(18.4)$ & $0.47(0.22-0.97)$ & 0.05 & & & $71(16.8)$ & $0.59(0.32-1.07)$ & 0.08 & & \\
\hline High & $23(6.5)$ & $0.04(0.001-2.01)$ & 0.11 & & & $23(5.5)$ & $0.45(0.14-1.41)$ & 0.17 & & \\
\hline MSI & & 1.37 (0.79-2.39) & 0.26 & & & & $1.62(0.98-2.66)$ & 0.06 & & \\
\hline dMMR & $97(27.4)$ & & & & & $107(25.4)$ & & & & \\
\hline pMMR & 257 (72.6) & & & & & 315 (74.6) & & & & \\
\hline
\end{tabular}



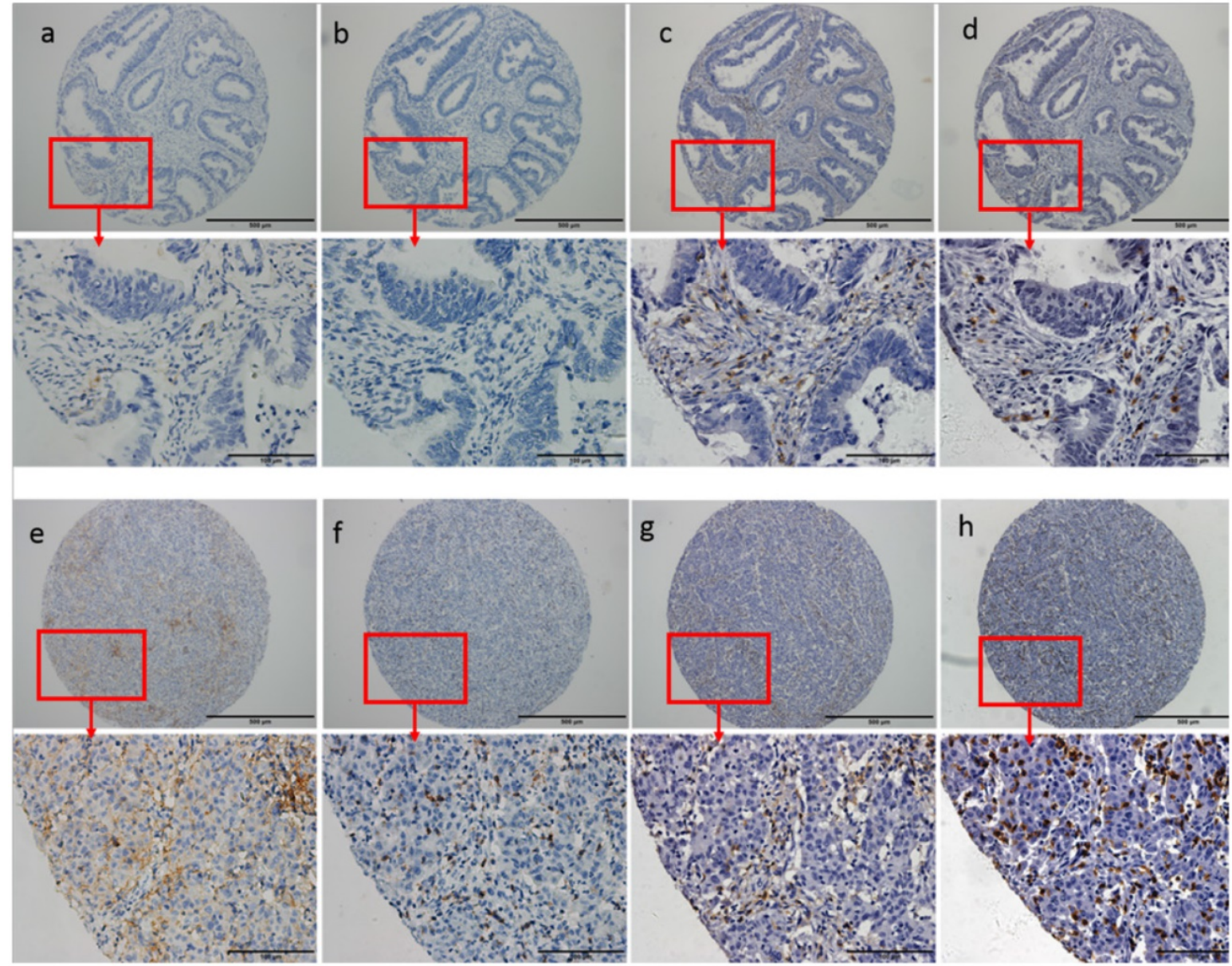

Figure 1. Representative immunostaining of PD-L1, PD-1, CD4 and CD8. Low PD-L1 expression (a, 0\%) was associated with low PD-1 expression (b, 0\%), low CD4 density (c, 15\%) and low CD8 density (d, 10\%). High PD-L1 expression (e, $20 \%$ in tumor infiltrating immune cells and $10 \%$ in cancer cells) was associated with high PD-1 expression (f, 10\%), high CD4 density (g, 30\%) and high CD8 density (h, 60\%)

The following factors were found to be significant predictive for OS by univariate analysis: sex (male/female), $\mathrm{T}$ category (T1+2/T3/T4), N category (N0/N1/N2), M category (M0/M1), tumor differentiation (poorly differentiated or undifferentiated/ moderately or well differentiated), tumor deposits (negative/positive) and PD-L1 expression (negative/positive, $P=0.02$ ). PD-L1 expression was associated with better OS (Figure 3). However, after being adjusted by other prognostic factors in multivariate analysis, PD-L1 expression was not an independent prognostic factor for OS (HR and 95\% CI: 0.81 (0.53-1.23), $\mathrm{P}=0.31$ ).

\section{The heterogeneity of PD-L1 expression in CRC}

Concordances of PD-L1 expression within primary tumor, between primary tumors and lymph node or distant metastatic tumors were respectively evaluated in 383, 105 and 64 paired cases. The inconsistency probability of PD-L1 expression was respectively $17.8 \%, 31.4 \%$ and $39.1 \%$ within primary tumor, between primary tumor and lymph node metastatic tumors, and between primary tumors and distant metastatic tumors. There were significant differences of PD-L1 expression rates within primary tumors $(P<0.001)$, between primary tumor and lymph node $(P<0.001)$ or distant metastatic tumors $(P=0.05)$ (Table 4).

Table 4. Concordance of PD-L1 expression within primary tumors, between primary tumors and lymph node or distant metastatic tumors.

\begin{tabular}{lclll}
\hline PD-L1 expression, No. (\%) & \multicolumn{2}{c}{ Primary tumors } & $\begin{array}{l}\boldsymbol{P} \\
\text { value }\end{array}$ & $\begin{array}{l}\text { Inconsistency } \\
\text { probability }\end{array}$ \\
\cline { 2 - 4 } $\begin{array}{l}\text { Negative } \\
\text { Another location in primary }\end{array}$ & & & $<0.001$ & $17.8 \%$ \\
tumors & $175(82.5)$ & $37(17.5)$ & & \\
$\begin{array}{l}\text { Negative } \\
\text { Positive }\end{array}$ & $31(18.1)$ & $140(81.9)$ & & \\
$\begin{array}{l}\text { Lymph node metastatic } \\
\text { tumors }\end{array}$ & & & $<0.001$ & $31.4 \%$ \\
Negative & $42(79.2)$ & $11(20.8)$ & & \\
$\begin{array}{l}\text { Positive } \\
\text { Distant metastatic tumors }\end{array}$ & $22(42.3)$ & $30(57.7)$ & & \\
Negative & $23(76.7)$ & 75.9 & 0.05 & \\
Positive & $18(52.9)$ & $16(47.1)$ & & $39.1 \%$ \\
\hline Abbreviations: PD-L1, programmed death ligand 1. &
\end{tabular}




\section{Discussion}

In this study, we found that PD-L1 expression was associated with less advanced $\mathrm{N}$ category and TNM stage, and less nervous invasion in CRC. Higher PD-L1 expression was correlated with dMMR status, higher PD-1 expression, higher CD4 and CD8 density. PD-L1 expression was an independent prognostic factor for DFS but not OS. In addition, there were significant discordance of PD-L1 expression within primary tumors, between primary tumors and lymph node or distant metastatic tumors, especially for the latter. To our knowledge, the sample size of our study was relatively large among similar studies and this was the first report about the special heterogeneity of PD-L1 expression in CRC.

There have already been ample investigations about the clinical and biomarker association of PD-L1 expression in CRC. But this study still has significance due to previous controversial findings. Several retrospective studies had investigated the clinicopathological association of PD-L1 expression in CRC, however, the conclusions were contradictory. Masugi, $Y$ et al. reported no clinicopathological correlation for PD-L1 expression ${ }^{19}$. In three studies with small samples, Rosenbaum, M W et al. ${ }^{20}$, Saigusa, $\mathrm{S}$ et al. ${ }^{21}$, and $\mathrm{Zhu}, \mathrm{H}$ et al. ${ }^{28}$ found that PD-L1 expression, as an indicator for high malignancy, was associated with poorer tumor differentiation, larger size, more venous invasion, more advanced $\mathrm{T}$ stage and more distant metastasis. By contrast, with a study including 1,420 CRCs, Droeser, R A et al. found PD-L1 to be related with early $\mathrm{T}$ stage, absence of lymph node metastasis, poor tumor differentiation and absence of vascular invasion ${ }^{29}$. This was in accordance with our study, which found PD-L1 expression to be significantly related with low malignant features of CRC.

According to the conclusions of previous studies, discordance also existed in the association of PD-L1 expression with MSI status, CD4 and CD8 density, as well as prognosis among previous studies 18-22. Excepting for the reason of different study population, different primary antibodies were probably another important cause. It had being noticed and discussed that detection of PD-L1 expression varied with different primary antibodies used by IHC 30,31 .

Though controversy might exist, theoretically, infiltration of immune cells, release of interferon- $\gamma$ could result in up-regulation of PD-L1 expression, which strongly indicated the association between PD-L1 expression with PD-1 expression, CD4 and CD8 density ${ }^{16,}{ }^{18}$. Tumors with dMMR had higher somatic mutation loads and more potential mutation-associated neoantigens, which facilitated immune active microenvironment and subsequent up-regulation of multiple immune checkpoints ${ }^{32,} 33$. Our findings were consistent with these points, and indicated PD-L1 expression to be a marker for immunogenic tumor in CRC.

Since PD-L1 expression could possibly be an indicator for immune reactivity, it might also be an indicator for good prognosis. However, in our study, PD-L1 expression only independently predicted better DFS, but not OS. Although it could be explained that OS might be influenced by more factors, especially treatment methods. This finding supported another possibility that anti-tumor immune responses might be more efficient and important for low load tumors. It was found that anti-CTLA4 treatment was more effective for melanoma patients with lower lactic dehydrogenase (LDH), an acknowledged marker of tumor loads 34,35 . Anti-CTLA4 treatment now had been proved to improve prognosis for adjuvant treatment in melanoma. Our study encourages that immune checkpoint modulation might also be tested for adjuvant treatment in CRC.

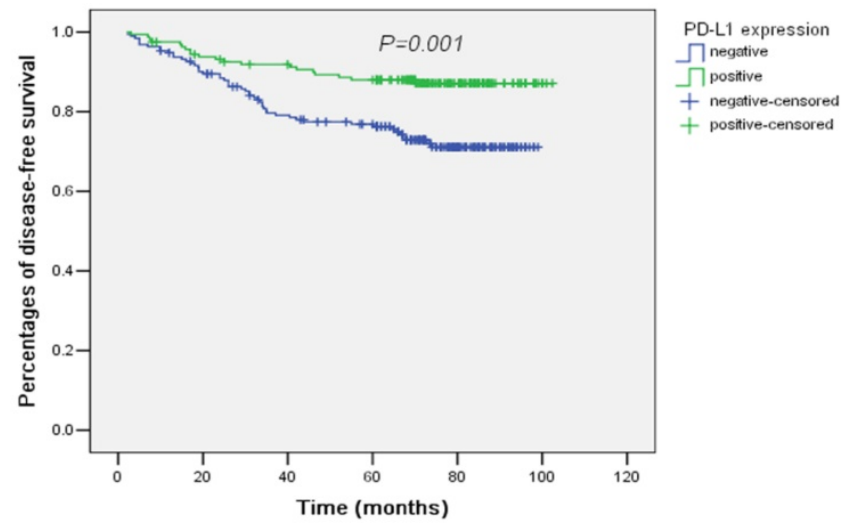

Figure 2. Survival curves of disease-free survival plotted by the Kaplan-Meier method according PD-L1 expression (negative/positive). PD-L1 expression was associated with better disease-free survival by univariate analysis $(P=0.001)$.

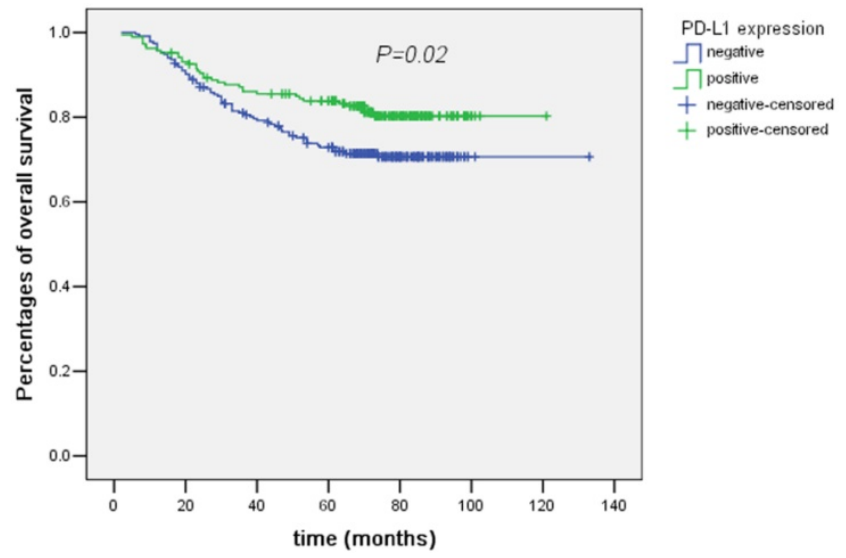

Figure 3. Survival curves of overall survival plotted by the Kaplan-Meier method according PD-L1 expression (negative/positive). PD-L1 expression was associated with better overall survival by univariate analysis $(P=0.02)$. 
The heterogeneity of PD-L1 expression had started to draw intensive research since PD-L1 expression had been found to be a possible efficacy predictive marker for anti-PD-1 treatment. Heterogeneity of PD-L1 expression between primary and metastatic tumors, between biopsies and resected tumors had been reported in lung cancer and clear-cell renal cell carcinoma ${ }^{36-39}$. However, reports about heterogeneous expression of PD-L1 in CRC were scarce. Our study was the first to report spatial heterogeneity of PD-L1 expression in CRC. We found that heterogeneity of PD-L1 expression was prominently remarkable in CRC, especially between primary and metastatic tumors. Thus primary tumor might not be suitable for detection of PD-L1 expression for advanced CRC patients. This finding of our study needs to be verified by further investigations.

PD-L1 expression was able to enrich target population for anti-PD-1 treatment in several cancers, including non-small cell lung cancer and gastric cancer. However, as presented in KEYNOTE-028, PD-L1 positive didn't efficiently predict better response to anti-PD-1 treatment in colorectal cancer. Our study revealed that the same as other cancers and in accordance with immunological theory, PD-L1 was a marker of previously existing anti-tumor immune activity in CRC, but its spatial heterogeneous expression was extremely obvious, which might impact its predictive efficiency for anti-PD-1 treatment to a certain extent.

Several limitations needed to be noted in this study. Firstly, it was retrospectively conducted. Selection bias couldn't be ignored, especially for stage IV patients, because only those with primary tumor resected were included in this study. Secondly, there were only 68 stage IV cases, we didn't analyze the predictive value of PD-L1 expression for PFS. Thirdly, most of the cases didn't have available information for molecular features, such as RAS mutation status. Thus the association of PD-L1 expression with molecular features was not assessed. Last but not least, we failed to use another independent cohort to validate the findings. However, our study was relatively large-sized and carefully conducted. Thus it's relatively reliable. Future studies are needed for validation the conclusions of our study, especially the finding of spatial heterogeneity of PD-L1 expression. Nevertheless, with a relatively large sample, our study proved PD-L1 expression to be a marker for immunogenic tumors in CRC. What's more, for the first time, we reported remarkable special heterogeneity of PD-L1 expression in CRC.

\section{Supplementary Material}

Supplementary table 1.

http://www.jcancer.org/v09p4325s1.pdf

\section{Acknowledgments}

The authors gratefully acknowledge Hui Sheng at State Key Laboratory of Oncology in South China for her helpful suggestion in IHC staining and Yun-Xin Lu at Department of Medical Oncology, Sun Yat-sen University Cancer Center for his assistance in TMAs construction. This study was supported by Natural Science Foundation of Guangdong Province (2014A030312015), Science and Technology Program of Guangdong (2015B020232008), and Science and Technology Program of Guangzhou (15570006, 201508020250, 201604020003).

This study is registered on http:/ / www.research data.org.cn, which is a website to deposit research data. The registration number is RDDA2018000748 for this study.

\section{Competing Interests}

The authors have declared that no competing interest exists.

\section{References}

1. Postow MA, Callahan MK, Wolchok JD. Immune Checkpoint Blockade in Cancer Therapy. J Clin Oncol. 2015;33:1974-82.

2. Sharon E, Streicher H, Goncalves P, Chen HX. Immune checkpoint inhibitors in clinical trials. Chin J Cancer. 2014;33:434-44.

3. Robert C, Ribas A, Wolchok JD, Hodi FS, Hamid O, Kefford R, Weber JS, Joshua AM, Hwu WJ, Gangadhar TC, Patnaik A, Dronca R, et al. Anti-programmed-death-receptor-1 treatment with pembrolizumab in ipilimumab-refractory advanced melanoma: a randomised dose-comparison cohort of a phase 1 trial. Lancet. 2014;384:1109-17.

4. Robert C, Long GV, Brady B, Dutriaux C, Maio M, Mortier L, Hassel JC, Rutkowski P, McNeil C, Kalinka-Warzocha E, Savage KJ, Hernberg MM, et al. Nivolumab in previously untreated melanoma without BRAF mutation. $\mathrm{N}$ Engl J Med. 2015;372:320-30.

5. Gyawali B, Ota A, Ando Y. Nivolumab in Nonsquamous Non-Small-Cell Lung Cancer. N Engl J Med. 2016;374:493.

6. Herbst RS, Baas P, Kim DW, Felip E, Perez-Gracia JL, Han JY, Molina J, Kim $\mathrm{JH}$, Arvis CD, Ahn MJ, Majem M, Fidler MJ, et al. Pembrolizumab versus docetaxel for previously treated, PD-L1-positive, advanced non-small-cell lung cancer (KEYNOTE-010): a randomised controlled trial. Lancet. 2016;387:1540-50.

7. Chow LQ, Haddad R, Gupta S, Mahipal A, Mehra R, Tahara M, Berger R, Eder JP, Burtness B, Lee SH, Keam B, Kang H, et al. Antitumor Activity of Pembrolizumab in Biomarker-Unselected Patients With Recurrent and/or Metastatic Head and Neck Squamous Cell Carcinoma: Results From the Phase Ib KEYNOTE-012 Expansion Cohort. J Clin Oncol. 2016;34(32):3838-3845.

8. Motzer RJ, Escudier B, McDermott DF, George S, Hammers HJ, Srinivas S, Tykodi SS, Sosman JA, Procopio G, Plimack ER, Castellano D, Choueiri TK, et al. Nivolumab versus Everolimus in Advanced Renal-Cell Carcinoma. N Engl J Med. 2015;373:1803-13.

9. Ansell SM, Lesokhin AM, Borrello I, Halwani A, Scott EC, Gutierrez M, Schuster SJ, Millenson MM, Cattry D, Freeman GJ, Rodig SJ, Chapuy B, et al. PD-1 blockade with nivolumab in relapsed or refractory Hodgkin's lymphoma. N Engl J Med. 2015;372:311-9.

10. Le DT, Uram JN, Wang $H$, Bartlett $B R$, Kemberling $H$, Eyring AD, Skora AD, Luber BS, Azad NS, Laheru D, Biedrzycki B, Donehower RC, et al. PD-1 Blockade in Tumors with Mismatch-Repair Deficiency. N Engl J Med. 2015;372:2509-20.

11. Sharon E, Streicher H, Goncalves P, Chen HX. Immune checkpoint inhibitors in clinical trials. Chin J Cancer. 2014;33:434-44.

12. Schalper KA, Velcheti V, Carvajal D, Wimberly H, Brown J, Pusztai L, Rimm DL. In situ tumor PD-L1 mRNA expression is associated with increased TILs and better outcome in breast carcinomas. Clin Cancer Res. 2014;20:2773-82.

13. Xie QK, Zhao YJ, Pan T, Lyu N, Mu LW, Li SL, Shi MD, Zhang ZF, Zhou PH, Zhao M. Programmed death ligand 1 as an indicator of pre-existing adaptive 
immune responses in human hepatocellular carcinoma. Oncoimmunology. 2016;5:e1181252.

14. Zhang L, Qiu M, Jin Y, Ji J, Li B, Wang X, Yan S, Xu R, Yang D. Programmed cell death ligand 1 (PD-L1) expression on gastric cancer and its relationship with clinicopathologic factors. Int J Clin Exp Pathol. 2015;8:11084-91.

15. Hamanishi J, Mandai M, Iwasaki M, Okazaki T, Tanaka Y, Yamaguchi K, Higuchi T, Yagi H, Takakura K, Minato N, Honjo T, Fujii S. Programmed cell death 1 ligand 1 and tumor-infiltrating CD8+ T lymphocytes are prognostic factors of human ovarian cancer. Proc Natl Acad Sci U S A. 2007;104:3360-5.

16. Abiko K, Matsumura N, Hamanishi J, Horikawa N, Murakami R, Yamaguchi K, Yoshioka Y, Baba T, Konishi I, Mandai M. IFN-gamma from lymphocytes induces PD-L1 expression and promotes progression of ovarian cancer. Br J Cancer. 2015;112:1501-9.

17. Garon EB, Rizvi NA, Hui R, Leighl N, Balmanoukian AS, Eder JP, Patnaik A, Aggarwal C, Gubens M, Horn L, Carcereny E, Ahn MJ, et al. Pembrolizumab for the treatment of non-small-cell lung cancer. $N$ Engl $J$ Med. 2015;372:2018-28.

18. Li Y, Liang L, Dai W, Cai G, Xu Y, Li X, Li Q, Cai S. Prognostic impact of programed cell death-1 (PD-1) and PD-ligand 1 (PD-L1) expression in cancer cells and tumor infiltrating lymphocytes in colorectal cancer. Mol Cancer. 2016;15:55.

19. Masugi Y, Nishihara R, Yang J, Mima K, Da SA, Shi Y, Inamura K, Cao Y, Song M, Nowak JA, Liao X, Nosho K, et al. Tumour CD274 (PD-L1) expression and T cells in colorectal cancer. Gut. 2017;66(8):1463-1473.

20. Rosenbaum MW, Bledsoe JR, Morales-Oyarvide V, Huynh TG, Mino-Kenudson M. PD-L1 expression in colorectal cancer is associated with microsatellite instability, BRAF mutation, medullary morphology and cytotoxic tumor-infiltrating lymphocytes. Mod Pathol. 2016;29(9):1104-12.

21. Saigusa S, Toiyama $Y$, Tanaka K, Inoue $Y$, Mori K, Ide S, Imaoka H, Kawamura M, Mohri Y, Kusunoki M. Implication of programmed cell death ligand 1 expression in tumor recurrence and prognosis in rectal cancer with neoadjuvant chemoradiotherapy. Int J Clin Oncol. 2016;21(5):946-952.

22. Lee LH, Cavalcanti MS, Segal NH, Hechtman JF, Weiser MR, Smith JJ, Garcia-Aguilar J, Sadot E, Ntiamoah P, Markowitz AJ, Shike M, Stadler ZK, et al. Patterns and prognostic relevance of PD-1 and PD-L1 expression in colorectal carcinoma. Mod Pathol. 2016;29(11):1433-1442.

23. Gao $Q$, Wang ZC, Duan M, Lin $Y H$, Zhou XY, Worthley DL, Wang XY, Niu G, Xia Y, Deng M, Liu LZ, Shi JY, et al. Cell Culture System for Analysis of Genetic Heterogeneity Within Hepatocellular Carcinomas and Response to Pharmacologic Agents. Gastroenterology. 2017;152(1):232-242.e4.

24. Spoerke JM, Gendreau S, Walter $K$, Qiu J, Wilson TR, Savage H, Aimi J, Derynck MK, Chen M, Chan IT, Amler LC, Hampton GM, et al. Heterogeneity and clinical significance of ESR1 mutations in ER-positive metastatic breast cancer patients receiving fulvestrant. Nat Commun. 2016;7:11579.

25. Wei L, Wang J, Lampert E, Schlanger S, DePriest AD, Hu O Gomez EC, Murakam M, Glenn ST, Conroy J, Morrison C, Azabdaftari G, et al. Intratumoral and Intertumoral Genomic Heterogeneity of Multifocal Localized Prostate Cancer Impacts Molecular Classifications and Genomic Prognosticators. Eur Urol. 2017;71(2):183-192.

26. Russo M, Siravegna G, Blaszkowsky LS, Corti G, Crisafulli G, Ahronian LG, Mussolin B, Kwak EL, Buscarino M, Lazzari L, Valtorta E, Truini M, et al. Tumor Heterogeneity and Lesion-Specific Response to Targeted Therapy in Colorectal Cancer. Cancer Discov. 2016;6:147-53.

27. Li ZZ, Bai L, Wang F, Zhang ZC, Wang F, Zeng ZL, Zeng JB, Zhang DS, Wang $\mathrm{FH}$, Wang ZQ, Li YH, Shao JY, et al. Comparison of KRAS mutation status between primary tumor and metastasis in Chinese colorectal cancer patients. Med Oncol. 2016;33:71.

28. Zhu $\mathrm{H}$, Qin $\mathrm{H}$, Huang $\mathrm{Z}$, Li S, Zhu X, He J, Yang J, Yu X, Yi X. Clinical significance of programmed death ligand-1 (PD-L1) in colorectal serrated adenocarcinoma. Int J Clin Exp Pathol. 2015;8:9351-9.

29. Droeser RA, Hirt C, Viehl CT, Frey DM, Nebiker C, Huber X, Zlobec I, Eppenberger-Castori S, Tzankov A, Rosso R, Zuber M, Muraro MG, et al. Clinical impact of programmed cell death ligand 1 expression in colorectal cancer. Eur J Cancer. 2013;49(9):2233-42.

30. Sun WY, Lee YK, Koo JS. Expression of PD-L1 in triple-negative breast cancer based on different immunohistochemical antibodies. J Transl Med. 2016;14:173

31. McLaughlin J, Han G, Schalper KA, Carvajal-Hausdorf D, Pelekanou V, Rehman J, Velcheti V, Herbst R, LoRusso P, Rimm DL. Quantitative Assessment of the Heterogeneity of PD-L1 Expression in Non-Small-Cell Lung Cancer. JAMA Oncol. 2016;2:46-54.

32. Le DT, Uram JN, Wang $H$, Bartlett $B R$, Kemberling $H$, Eyring AD, Skora AD, Luber BS, Azad NS, Laheru D, Biedrzycki B, Donehower RC, et al. PD-1 Blockade in Tumors with Mismatch-Repair Deficiency. N Engl J Med. 2015;372:2509-20.

33. Llosa NJ, Cruise M, Tam A, Wicks EC, Hechenbleikner EM, Taube JM, Blosser RL, Fan H, Wang H, Luber BS, Zhang M, Papadopoulos N, et al. The vigorous immune microenvironment of microsatellite instable colon cancer is balanced by multiple counter-inhibitory checkpoints. Cancer Discov. 2015;5:43-51.

34. Felix J, Cassinat B, Porcher R, Schlageter MH, Maubec E, Pages C, Baroudjian B, Homyrda L, Boukouaci W, Tamouza R, Bagot M, Caignard A, et al. Relevance of serum biomarkers associated with melanoma during follow-up of anti-CTLA-4 immunotherapy. Int Immunopharmacol. 2016;40:466-73.

35. Martens A, Wistuba-Hamprecht K, Geukes FM, Yuan J, Postow MA, Wong P, Romano E, Khammari A, Dreno B, Capone M, Ascierto PA, Di Giacomo AM, et al. Baseline Peripheral Blood Biomarkers Associated with Clinical Outcome of Advanced Melanoma Patients Treated with Ipilimumab. Clin Cancer Res. 2016;22:2908-18

36. Callea M, Albiges L, Gupta M, Cheng SC, Genega EM, Fay AP, Song J, Carvo I, Bhatt RS, Atkins MB, Hodi FS, Choueiri TK, et al. Differential Expression of PD-L1 between Primary and Metastatic Sites in Clear-Cell Renal Cell Carcinoma. Cancer Immunol Res. 2015;3:1158-64.

37. Ilie M, Long-Mira E, Bence C, Butori C, Lassalle S, Bouhlel L, Fazzalari L, Zahaf K, Lalvee S, Washetine K, Mouroux J, Venissac N, et al. Comparative study of the PD-L1 status between surgically resected specimens and matched biopsies of NSCLC patients reveal major discordances: a potential issue for anti-PD-L1 therapeutic strategies. Ann Oncol. 2016;27:147-53.

38. Mansfield AS, Aubry MC, Moser JC, Harrington SM, Dronca RS, Park SS, Dong $\mathrm{H}$. Temporal and spatial discordance of programmed cell death-ligand 1 expression and lymphocyte tumor infiltration between paired primary lesions and brain metastases in lung cancer. Ann Oncol. 2016;27:1953-8.

39. Pinato DJ, Shiner RJ, White SD, Black JR, Trivedi P, Stebbing J, Sharma R, Mauri FA. Intra-tumoral heterogeneity in the expression of programmeddeath (PD) ligands in isogeneic primary and metastatic lung cancer: Implications for immunotherapy. Oncoimmunology. 2016;5(9):e1213934. 